\title{
E-recruiting Platforms: Features that Influence the Efficiency of Online Recruitment Systems
}

\author{
Ondina ROSOIU, Cristian POPESCU \\ Bucharest University of Economic Studies, Romania \\ ondina.rosoiu@yahoo.ro,crip.popescu@gmail.com
}

Twenty active e-recruitment platform users took part in this study for discovering the most asked for features in a web based hiring process. The respondents were chosen based on their history on such recruitment platforms. With the help of our Internet users we narrowed down the number of platforms, to research for outstanding features and tool efficiency, to five most impressive ones (e-jobs, hipo, bestjobs, LinkedIn, Freelancer). The results were as useful as we expected when we proposed an investigation related to the future of web recruiting platforms. They underlined in a specific manner that most of such web platform users need to have a professional and fully functional environment where they can list their accomplishments and experience and receive direct feedback from employers or employees. The study also shows in detail how much and why do users like to have certain functionalities when they are searching for a new job.

Keywords: Human Resource, Recruitment Platforms, Features, Job Seekers, E-recruiting

$\mathbf{1}^{1}$ Introduction

Human resources recruitment and selection processes are vital for an organization that wants not only to survive on the market but also to increase its position in the market it operates on.

The selection process for human resources in a company must be very well structured and planned. Through the appearance and evolution of new technologies, the recruitment is progressive influenced by the Internet. Also, the specialists needed in terms of quality and quantity cannot be found easily and financial resources are often limited. As a result of this, the article describes the online recruitment and selection of human resources which is a process that involves minimum cost and filling vacancies is achieved in the shortest amount of time.

Online job sites have revolutionized the recruitment landscape for both employers and job seekers and largely increased the efficiency with which hiring decisions can take place. E-recruiting is like any recruiting processes that a business organization conducts using web-based tools and based on the online job sites, the recruitment landscape for both employers and job seekers has revolutionized. Also, the efficiency of hiring decisions has largely increased. At the moment, there are more than thousands of online platforms competing for the job seekers attention as the benefits of online recruitment usage has raised and the way candidates search for job and companies hire revolutionized in a very short time.

Using the online recruitment platforms, the job seekers could also find out if the searched company offers meal tickets, medical insurances, financial support for training and laptops. These benefits can be noted on the company side, for when a job is posted but also could be noted on the user profile so that it communicates directly his demands. Internship and practice stages can also be published on sites so that students and those that wish to develop a specific skill. This should also mention the possibility of continuing with a job to that company and the number of places available.

The main objectives of the research is to highlight the advantages and the disadvantages of e-recruiting platforms, to make a comparison between the top of them and also to come up with some ways to improve the functionalities of the platforms to provide job seekers the easiest and efficient mode to navigation for the purpose of finding the ideal job for them. 


\section{Literature Review}

Due to the fact that the Internet and technology have grown rapidly over the past years, at the same time, the e-recruiting domain is growing and the job seekers have a lot of online recruitment platforms that they can use to find the desired job. The goal of the e-recruitment platforms is to identify and to attract the potential employees and because is also easily to select the employees is case of long distances, the e-recruiting platforms are now widely used by both recruiters and people looking for jobs either in Romania or in the whole world ([1]).

E-recruiting manner has a lot of benefits despite the classic manner as for recruiters it is easy to stay up to date with the changes in the market regarding employees, due to the databases available and all that high quality information stored aid the Internet. Also for employees it is easier to find jobs in any field. There is also the fact that it is easy to upload the CV with their experience, accuracy of information and they get contacted directly by the recruiter. The reach grows when the users can reach from small to big companies and corporations the same way for every option ([3]).

The geographic positioning has no border now; it does not restrict anyone to apply for a job in another country, or continent. Different kind of available jobs can reach to different kind of people, new ways to manage jobs and recruit people ([4]).

The online recruitment is a more efficient way to recruit also because the companies can save costs by reducing revenue using online recruitment and also by winning the time that would have been assigned to a classic manner that would have required a lot of time allocated. Also, using this type of platforms, the candidates who are suitable for the post can be easily selected ([6]).

E-Recruitment allows for immediate real-time interaction and $24 \times 7$ hiring/job search activity. Also the posts are available for about 30 days and can continue to receive applicants after it expires. The e-recruitment hiring is on average $70 \%$ faster than traditional hiring methods and the recruiting cycle is speeded up at every stage from posting, to receiving CVs to filtering to managing the contacts and workflow. The available filtration tools on these kinds of sites also help a lot to find a job or a recruit. The article states that Bayt.com can offer up to 33 filters to distinguish candidates. The author states some available features of this site which contains the possibility for companies to step up their game through Ads in their site, which links directly to their job offering. This can help grow the level of visibility of the company ([10]).

Aside from the functionalities that need to be implemented in one's platform we also need to know the numbers that affect the search of jobs in the Romanian community. The team of hipo.ro managed to conclude a survey on HR companies that need to find and hire employees in the year of 2016. This survey was done using a web platform and it included respondents from HR consultants, directors, managers, CEOs, team leaders, project managers, HR specialists, training coordinators and other related functions that could give out a relevant view on the employment market in the next period. The companies that took part of this survey have different domain activity like recruiting agencies, insurances, banks, constructions, energy, engineering, e-commerce, media, IT software and hardware development, retail, Telecom and professional services. Regarding the growth of the company in the next year a number of $40 \%$ of the respondents said that they predict an increase in the number of employees by more than $10 \%$. This means that the job platforms should emphasis on the search of new jobs and concentrate on developing interactive and fast responsive software. The departments with the biggest increase in employees are of course IT software with a percentage of $16.6 \%$, sales with $12.95 \%$, costumer support $(11.67 \%)$ and engineering with $9.28 \%$. These are the biggest interests for the near future of these companies and e-recruiting platform should know that if they want to benefit in this area. Beside this fact, they should offer variety in the job field so that every user of the site to be equally offered the possibility of finding a job ([14]). 


\section{Methods}

The study for this article is based on an online survey due the fact that our goal is to find out, based on a group of people which are the most successful online recruitment platforms and, as Gable G.G. also mentioned, this method is very useful because, based on their opinion about each of the platform mentioned in our questionnaire, we can easily find out what people need, which of online recruitment platforms they use most often and what these platforms can provide for a better experience. It is also very important that the sample used for the research to be representative.

\section{Descriptions}

The online survey has 10 questions regarding the following five online recruitment platforms: www.e-jobs.ro, www.freelancer.com, www.hipo.ro, www.linkedin.com, www.bestjobs.ro. We chose these five online recruitment platforms because, according to www.trafic.ro, these are some of the top online recruiting platforms, mentioned as being some of the most popular platforms where people post their $\mathrm{CV}$ to find jobs in various domains and our goal is to find which are the highest rated.
The target group that is used for the research consists of 19 people who used at least one time an online platform specialized on the recruitment of new employees. We got some respondents that have never used or heard anything about none of the recruitment platforms that we selected, so will be removed from our analyses to ensure that we will get relevant results to our goal. The selection of the respondents was made through age groups and based on male or female differences. We will see later how that influences the users to use or not use a certain platform.

\section{The Results Analysis}

For our research we will analyse the answers of 19 participants. This can be considered a representative group for the users that use online recruiting platforms due to the fact that 95\% of the respondents have used the e-recruiting manner at least once. Another respondent categorization is the sex, which is dominated by males. This is a consequence of IT background of most of our respondents which is formed mainly of males. The respondents were classified by an age group so that we can extract the preferences based on that (Figure 1).
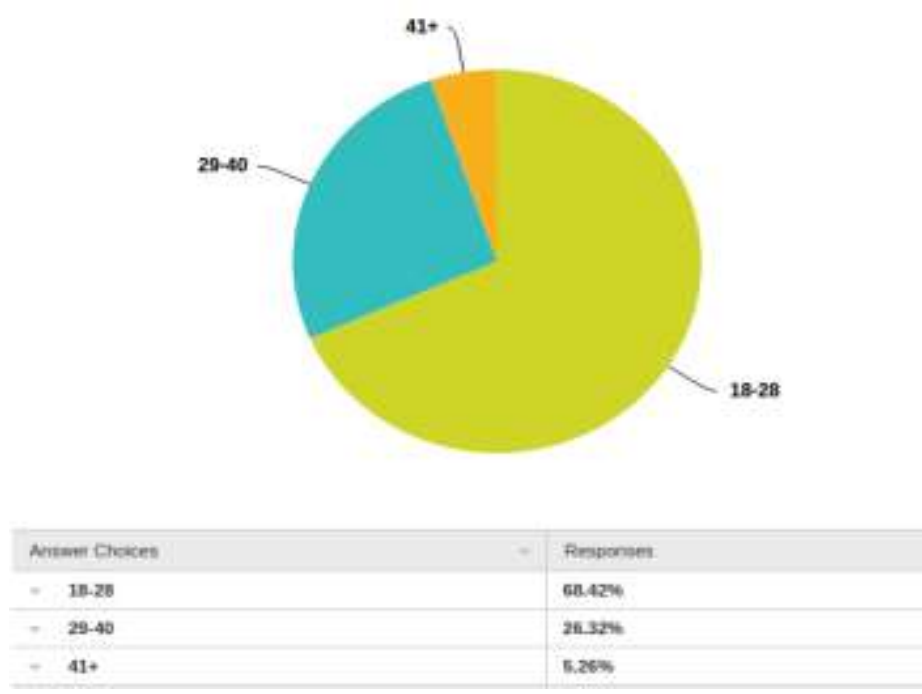

Fig. 1. Age group classification

We realised is that our respondents ages are most between 18-28 with a percentage of $68.42 \%$, followed by the $29-40$ of age users.
The youth is more attracted by the online recruitment and uses it more often than the elder people. This is due to the fact that young people are looking for new jobs and because they 
are in constant changes to find the best job for them. Opus young people, older people already have steady employment and seniority in the respective field.

Analysed platforms; In our online survey we used a specific set of platforms that are popu- lar and we asked our users which are the platforms they heard about and the platform they use to find jobs or different offers (Figure 2). The opinions were important for our study in order to develop an idea regarding the popularity of each platform from their point of view.

Did you ever heard of any of these platforms?

Answered in shippedit

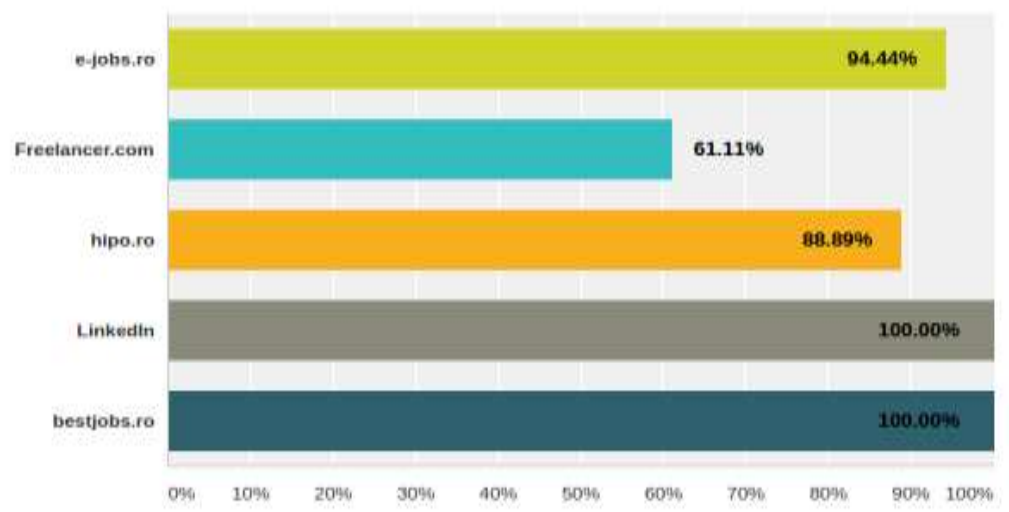

\begin{tabular}{|l|lr}
\hline Answer Choices & Responses & \\
\hline - E-jobs.ro & $94.44 \%$ & 17 \\
\hline Freelancer.com & $61.11 \%$ & 11 \\
\hline hipo.ro & $\mathbf{8 8 . 8 9 \%}$ & 16 \\
\hline - Linkedin & $\mathbf{1 0 0 . 0 0 \%}$ & 18 \\
\hline - bestjoba.ro & $100.00 \%$ & 18 \\
\hline
\end{tabular}

Fig. 2. Platform popularity

Figure 3 indicates that all the selected sites are familiar to our respondents but we need to pay closer attention to LinkedIn and bestjobs.ro as they seem to be the most popular. These sites influence our decision to select which are the best features that they offer to their users. Also, we asked our respondents if they ever used such sites and the leaders remain the same, with a small disadvantage for bestjobs. Also, the use of e-jobs is significant raising almost the same as bestjobs, which means that they both have features that are important for our job seekers. 


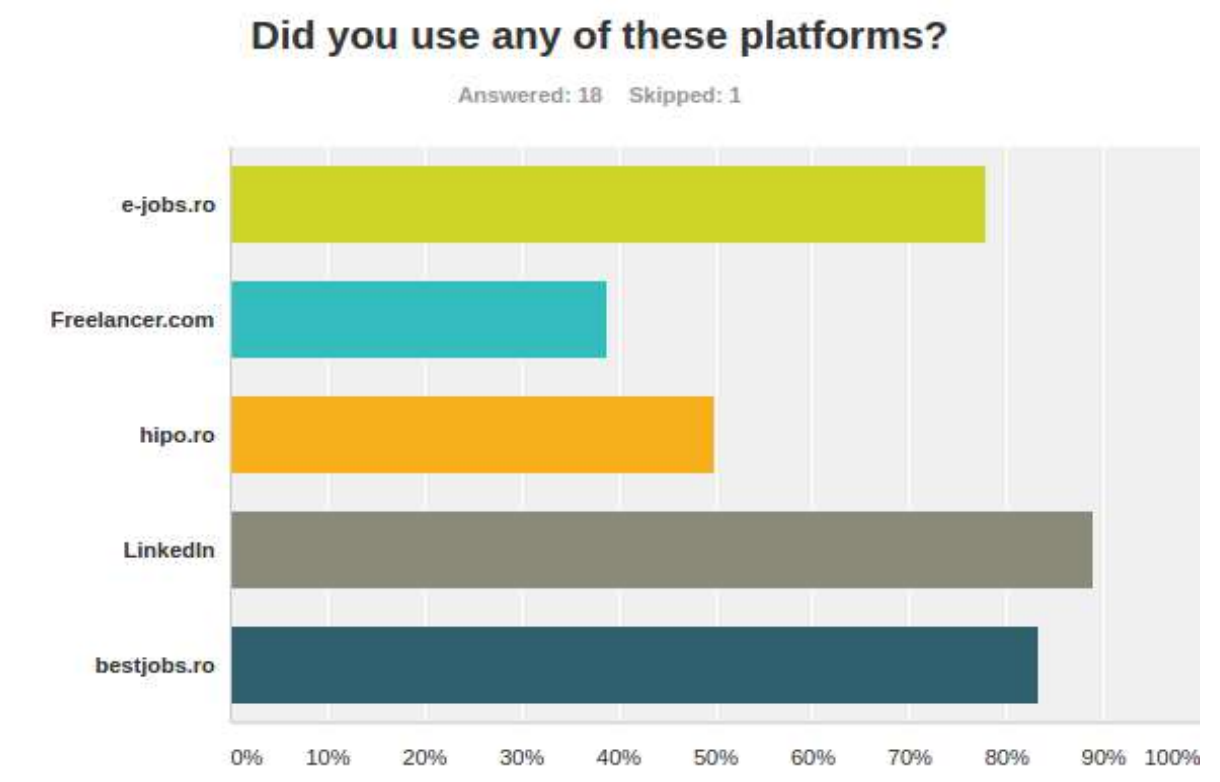

\begin{tabular}{|l|lc}
\hline Answer Choices & Responses & \\
\hline e-jobs.ro & $77.78 \%$ & 14 \\
\hline Freelancer.com & $38.89 \%$ & 7 \\
\hline hipo.ro & $50.00 \%$ & 9 \\
\hline Linkedln & $\mathbf{8 8 . 8 9} \%$ & 16 \\
\hline bestjobs.ro & $\mathbf{8 3 . 3 3 \%}$ & 15 \\
\hline
\end{tabular}

Fig. 3. Platforms usage

The preferences. The users' desires are the most important because they are the main purpose behind the development of online recruitment platforms. The clients are always right so we asked them to try to put in order the sites based on their interaction with them and tell us how they would classify the one they prefer. Obviously the most satisfying platform was LinkedIn, being the most popular one, it got the most usage from their clients. After them comes e-jobs.ro which harvested a $25 \%$ on first place from the respondents. Bestjobs ended up being the platform placed on the 2nd-place and e-jobs on the 3rdplace.
The intervals. Most of the users exposed their preference of having a feature that actually informs them of new opportunities. This is very important for them based on our survey results, because they are periodically informed about different events and they just need to update their details on the platform. We can conclude, based on Table 1, that due to the fact that most of our respondents have never used Freelancer.com we concluded, based on our survey that it got a bad score compared to the others and that it is not appreciated by our job seekers as being a high rated online recruitment platform. 
Table 1. Platforms access frequency

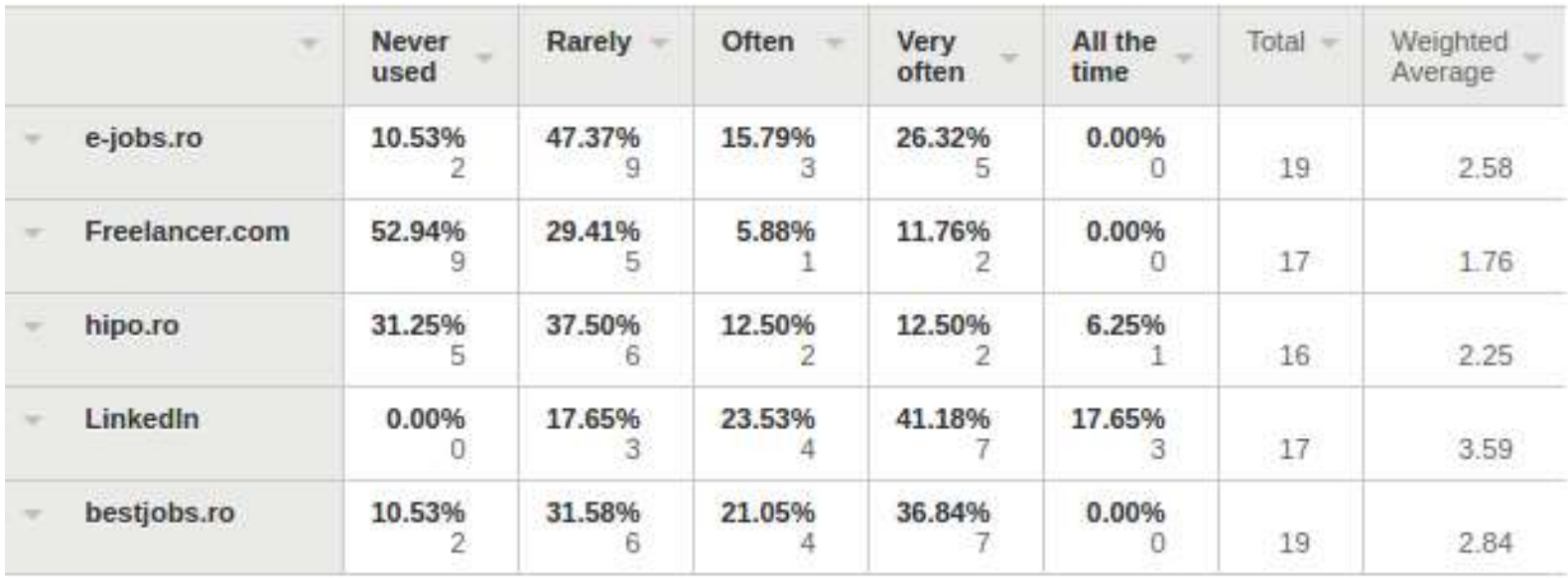

A great feature to implement on e-recruiting website is the notification functionality which is appreciated by most of our respondents. The site needs to have a periodic notification system that informs the users about new opportunities or messages that they have received from recruiters. LinkedIn is the most powerful on this chapter leading with the most votes, based on the fact that they have a really efficient notification system for new jobs, new messages and news. This feature keeps the job seekers strongly focused on the finding of the best job. Weekly or daily newsletter is also appreciated among our subjects. This is also a way of sharing job opportunities for the platform's clients.

The success rate. Another important fact about recruitment platforms is the success rate. Here this is based $100 \%$ on the respondent's history on these sites. In addition to the cool features and nice user interface, we wanted to know if the platform really deserves to be used and if it offers indeed many benefits to the users. As it is shown in Table 2, the number of calls or e-mails received is a way to measure the efficiency that you got from the site. Being the most used site from our users, LinkedIn was the leader of most being reached column). Bestjobs and LinkedIn helped half of our subjects to go to an interview and interact directly with the recruiters. A major aspect for this is the number of existing users, on both sides. We need a great number of recruiters so that our job seekers will find a job and be chosen for an interview with the respective company. An average of $47.37 \%$ of our respondents got hired using one of these platforms. This means that the recommendation system is still being promoted and these online recruitment websites not yet fulfil the required trust to hire someone from outside

Table 2. Platforms efficiency

\begin{tabular}{|c|c|c|c|c|c|c|c|}
\hline$\psi$ & $\begin{array}{l}\text { Never } \\
\text { used }\end{array}$ & $\begin{array}{l}\text { No } \\
\text { replies } \\
\text { from } \\
\text { recruiters }\end{array}$ & $\begin{array}{l}\text { I was } \\
\text { reached }\end{array}$ & $\begin{array}{l}\text { I went to } \\
\text { some job } \\
\text { interviews }\end{array}$ & $\begin{array}{l}\text { Felt } \\
\text { really } \\
\text { popular! }\end{array}$ & Total = & $\begin{array}{l}\text { Weighted } \\
\text { Average }\end{array}$ \\
\hline e-jobs.ro & $\begin{array}{r}10.53 \% \\
2\end{array}$ & $\begin{array}{r}31.58 \% \\
6\end{array}$ & $\begin{array}{r}21.05 \% \\
4\end{array}$ & $\begin{array}{r}36.84 \% \\
7\end{array}$ & $\begin{array}{r}0.00 \% \\
0\end{array}$ & 19 & 2.84 \\
\hline Freelancer.com & $\begin{array}{r}52.94 \% \\
9\end{array}$ & $\begin{array}{r}17.65 \% \\
3\end{array}$ & $\begin{array}{r}23.53 \% \\
4\end{array}$ & $\begin{array}{r}5.88 \% \\
1\end{array}$ & $\begin{array}{r}0.00 \% \\
0\end{array}$ & 17 & 1.82 \\
\hline hipo.ro & $\begin{array}{r}35.29 \% \\
6\end{array}$ & $\begin{array}{r}29.41 \% 6 \\
5\end{array}$ & $\begin{array}{r}23.53 \% \\
4\end{array}$ & $\begin{array}{r}11.76 \% \\
2\end{array}$ & $\begin{array}{r}0.00 \% \\
0\end{array}$ & 17 & 2.12 \\
\hline Linkedln & $\begin{array}{r}0.00 \% \\
0\end{array}$ & $\begin{array}{r}11.76 \% \\
2\end{array}$ & $\begin{array}{r}35.29 \% \\
6\end{array}$ & $\begin{array}{r}41.18 \% \\
7\end{array}$ & $\begin{array}{r}11.76 \% \\
2\end{array}$ & 17 & 3.53 \\
\hline bestjobs.ro & $\begin{array}{r}5.26 \% \\
1\end{array}$ & $\begin{array}{r}21.05 \% \\
4\end{array}$ & $\begin{array}{r}21.05 \% \\
4\end{array}$ & $\begin{array}{r}52.63 \% \\
10\end{array}$ & $\begin{array}{r}0.00 \% \\
0\end{array}$ & 19 & 3.21 \\
\hline
\end{tabular}


The features. From the features preference point of view (Table 3), we found out from our respondents which are the features that actually draw them to a certain platform or the other. Based on preference we offered options to select the user interface of the platform, the exposures that were supplied through that site, the gratuity that came with the use of the site and finally the notification system. We extracted the results based on the features that the users have chosen.

Table 3. Features preference

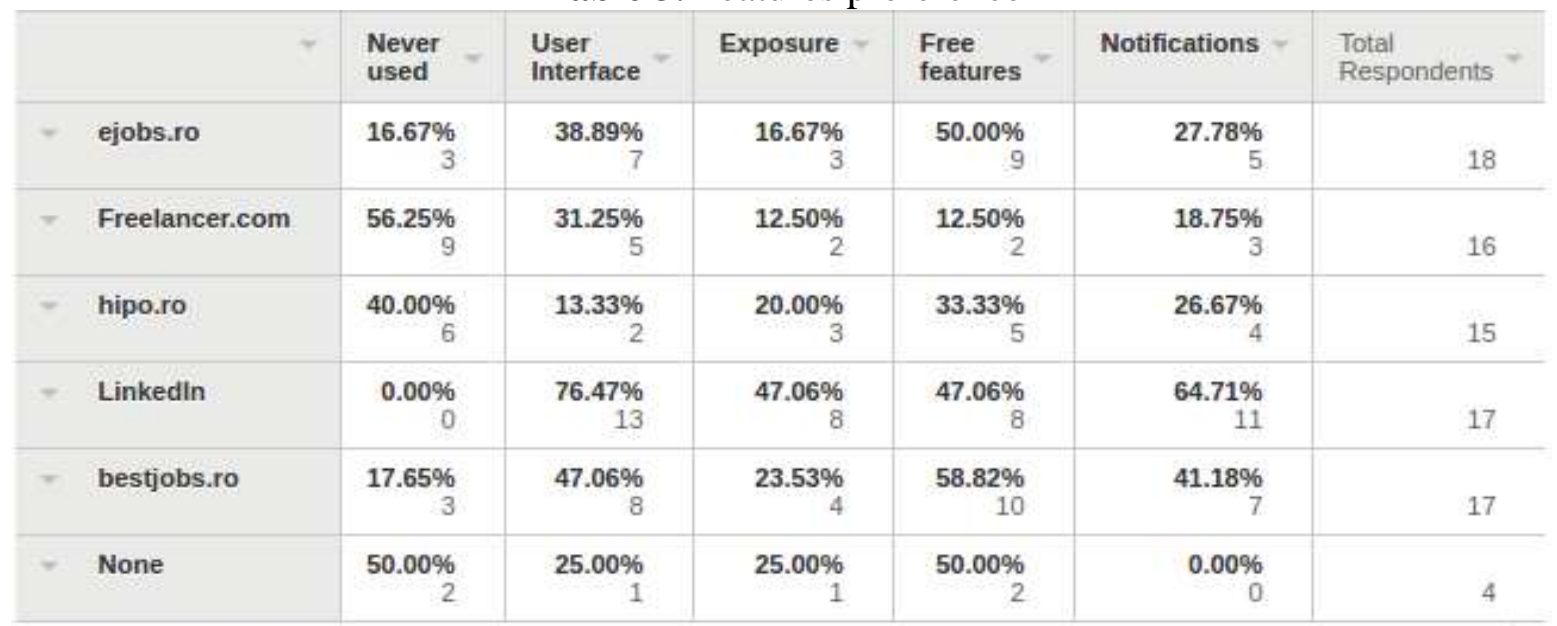

\section{a. User Interface}

The user interface is an important aspect, as we expected and this came out just right from the survey. LinkedIn is above all with $76.47 \%$ of respondents that vote for its user interface. Also, bestjobs got an interesting $47.06 \%$ for this graphic characterization of the platforms. It has a nice, easy to use interface with easyto-apply-to-jobs utility.

\section{b. Exposure}

The respondents have been asked to input their opinion regarding how the usage of a specific platform helped them getting better exposure on the market. Here, the number of recruiters presents on the platform counts a lot. So, as far as we can see, Freelancer is not so popular within our respondents and it got the smallest percentage. LinkedIn is leading with $47.06 \%$ of its users felt that their skills were exposed better on this website.

\section{c. Free features}

Over $58 \%$ of our job seekers have checked this functionality for bestjobs. This is considered to be very important in the choice of the platform by our subjects. E-jobs counts here with $50 \%$ of respondents selecting the free utility. The usage of these sites with most free features becomes easier.

\section{d. Notifications}

As it was specified earlier the notification system is one of the most important features existing on an online recruitment platform. The user has to know right away if he was contacted or a new job in his or hers work domain has appeared. This is an efficient way to keep the user in alert and to help him not lose opportunities.

Bestjobs got an average of $41.18 \%$ from its users for having a great notification system, including newsletters and messages. LinkedIn is due to the size of the platform, the leader in this act.

\section{Discussions}

Related to what information we had before this study, we can now find ourselves more certain about what we need and want to obtain from such a useful tool. When in search of a place of business every one of our survey takers had mentioned that the Internet was the first option. This means that the first choice 
was suggested by their closest Internet search engine available. What this means, is that the popularity of the site is very important and the way it sells itself to the public.

Also, it is very important the way job seekers display themselves on their profile. This has great value in the eyes of a recruiter that is searching for a professional. The profile should be completed with details related to the studies they graduated, the languages skills they have so that it creates a more relevant profile for the recruiters. Other useful specifications should include the mention of extracurricular activities, foreign studies and good academic grades. Beside the hard skills that need to be noted in a profile from a jobs platform, the soft skills are also as important today. We can include here communication, result orientated concentration, flexibility and adaptability which are the most important. The skill completion needs to be well categorized and easy to use. Such skills are a must have in any organization and need to be noted with different grades or standards. Other capabilities that are looked for are problem solving, efficiency, time management, leadership and so on. These options should have a predefined template for formalization in the site so that the search for recruiters is much easier.

The user profile should also contain the user's preferences regarding the next job place. Benefits offered from employers are also as important as the job seeker's skills that he puts on the table. This is relevant for many of those that are looking into another job. This would simplify their job searching by the benefits that a company is offering.

It would be interesting if E-recruiting platforms implement a feature designed to offer some feedback and helpful information to the users, by periodically interviewing company recruiters and sharing important knowledge on how they should arrange and display themselves there. Periodic articles and success stories could have a good impact for the users' community.

The results obtained from our research show that users need a platform available to use for free when using its most basic features. This issue is a very burning concern of our modern users. Access to information needs to be highly prioritized and offered to the end user by the platform developers. Notifications play an obviously important role between the needed functionalities and the users. This got a high percentage of importance and evaluated as a high priority. This choice of a feature was selected by most of our users due to the fact that their need to be well informed regarding the opportunities that are being offered on the platform.

After all, we can extract the features that were the most appreciated, but in the end this depends on each user's personal preference of what platform is best suited for him or her. To resume to the most appreciated features we will mention notification, gratuity and exposure. These are the "must haves" to be able to develop a successful web-based e-recruiting platform.

\section{Conclusions}

Comparing different e-recruiting platforms, even though they activate on the same domain, is not an easy task. With the use of this study we need to draw some conclusion regarding the opinions of the public on this particular issue. The research reveals which are the must have functions of the online recruitment platforms in order to succeed. With these results the features of a future development in this industry will be easier. The planning of such a development has to be rigorous and exact because a stable foundation is what the customers trust and use.

The combinations of age and sex of the respondents and their choices in the questionnaire are what is relevant for the interface that is presented to them. A site that wants to attract people from all categories and ages needs to mix a lot of basic preferences to expose a pleasant navigation and attractiveness. The interface has to create display a high level of professionalism due to the domain that it is activating in. This means that it has to be simple but in the same time should expose the main functionalities that it has to offer. For the interface, the use of neutral and calm colours is the right way to go. We can take the main example from LinkedIn which has crushed its 
competitors on this aspect. The site has an easy to use, grey with blue responsive interface which allows anyone to navigate without being distracted or interrupted. Also, here comes in the free features that it exposes, without commercials popping up in the middle of the screen. On the same level, bestjobs has a winner interface and goes straight in the business level offering easy access to posted jobs.

A good way to attract users is to use social networks for advertise. The marketing department for a recruiting platform has to generate a big movement of sending the information to the public. With this functionality in place, the exposure for clients comes by itself. The recruiters that are present on the e-recruiting website are able to access a big number of job seekers directly and the other way around. LinkedIn is a good example with its rating system and recommendation functionalities. This is a great way of displaying the recruits to the recruiters, thus creating exposure.

The free features are most important for all users, but paid ones make the difference. We need to offer our customers the ability to access great functionalities like creating profiles, sharing profiles and showing themselves in a professional way to the others. In order to earn profit from this development process, every platform should have premium features like statistics, relevant suggestions and better job seeker filters. This should let the users to use this tool to obtain their results and complete their tasks, but also let them now that there are features that are available, in exchange for money that will make their experience even better. Millions of users are seeking and offering jobs on LinkedIn at totally no cost at all. This attracted a lot of clients for them of both payers and free users.

One of the most useful functionality has a great impact on our research and that is the notification system. This has raised LinkedIn above all the others because they compose personalised news letters and offer a very responsive messaging service. Users of the platform are able to contact each other and share job recommendations or even news, similar to a basic social network. This is a good way to create work relations and getting a good exposure to the desired contacts.

\section{References}

[1] N. Sharma. (2014). "Recruitment Strategies: A power of E-Recruiting and Social Media".

[2] G. G. Gable, "Integrating Case Study and Survey Research Methods: An Example in Information Systems," European Journal of Information Systems, Vol III, No 2, 1994, pp.112-126.).

[3] G. A. Brezoiu. (2014). "How Social Media Recruitment Influences Organizational Social Responsibility".

[4] C. Pantea, C. Păunescu. "Online Marketing Tools Used by Recruitment Portals - an Exploratory Research of the Romanian Market".

[5] T. Thielsch, Meinald, L. Träumer, and L. Pytlik. "E-Recruiting and Fairness: The Applicants' Point Of View". Information Technology and Management 13.2 (2012): 59-67. DOI:10.1007/s10799-0120117-x.

[6] V. P. Bresfelean, O. Veres and C. Bologa. (August 2010). "Competencies and Online Recruiting for Banking Occupations".

[7] J. Trivedi, Dr. A. Muduliolar, SPM, PDPU-Gandhinagar, Gujarat. (2015) "Research on Recruitment Outcomes and Recruitment Methods under the Mediating Impact of Credibility \& Satisfaction".

[8] J. F. Wolfswinkel. (June 2009). "Reflecting on e-Recruiting Research: a Systematic Literature Review".

[9] E. Furtmüller, C. Wilderom, Rolf van Dick. (2010). "Sustainable e-Recruiting Portals: How to Motivate Applicants to Stay Connected throughout their Careers?".

[10] J. Wolfswinke, E. Furtmueller, C. Wilderom, "Reflecting on E-Recruiting research Using Grounded Theory". "The Benefits of Online Recruitment". Bayt.com. N.P., 2016. Available: http://www.bayt.com/en/career-article$1121 /$.

[11] "Comparison of the Top 4 Freelancing 
Websites". Ladybird Ink. N.P., 2013. Available:

https://ladybirdink.net/2013/05/24/compa rison-of-freelancing-websites/ .

[12] D. Nevogt. (2014). "Comparing the Best

Freelance Websites". Time Tracking Software. N.P.

[13] L. Hebberd. (2013). "Why employee referrals are the best source of hire", Retrieved December 30, 2013, Available: http://theundercoverrecruiter.com/infogra phic-employeereferrals-hire/ .

[14] (2016). "Piata fortei de munca in 2016" Available: http://www.hipo.ro/locuri-demunca/get_raporthipo

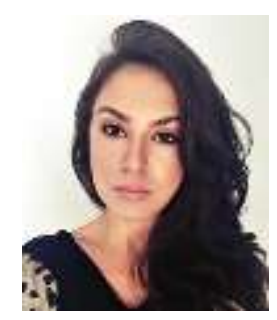

Ondina ROSOIU has graduated the Faculty of Cybernetics, Statistics and Economic Informatics in 2014. Currently she is student in the second year at the Master Program of Economic Informatics Department at Faculty of Cybernetics, Statistics and Economic Informatics from the Bucharest University of Economic Studies, Bucharest. In 2014 followed an internships at an international company that develops using .NET. In 2015 she started working in a company which is a global leader in the financial software market and she is a Technical Support Engineer programming with $\mathrm{C}++$ and $\mathrm{C \#}$ software development programs.

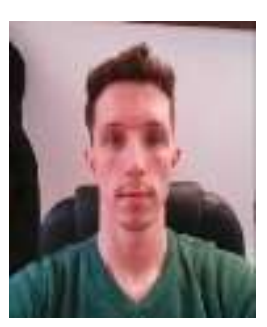

Cristian POPESCU has graduated the Faculty of Economic Cybernetics, Statistics and Informatics in 2014. He worked as a Web Developer developing a platform for a known Romanian market study company. In 2012 he started working full time for a computer networking company. In 2015 has started working in a small company developing full-stack java platform for various customers. His focus is mainly on using latest Java Technologies and developing good practice software. 